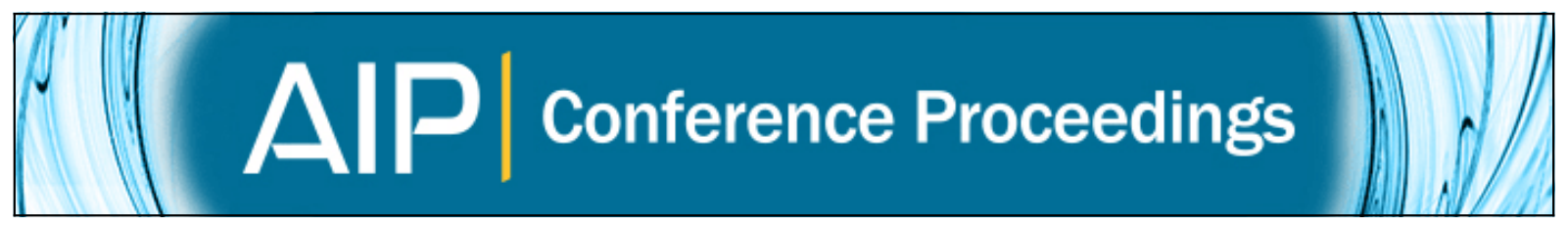

\title{
Small-scale spatial variations of shortwave downward radiation
}

Ralf Becker, Petra Gebauer, and Klaus Behrens

Citation: AIP Conference Proceedings 1531, 500 (2013); doi: 10.1063/1.4804816

View online: http://dx.doi.org/10.1063/1.4804816

View Table of Contents: http://scitation.aip.org/content/aip/proceeding/aipcp/1531?ver=pdfcov

Published by the AIP Publishing

Articles you may be interested in

Evaluation of a relationship between aerosols and surface downward shortwave flux through an integrative analysis of a global aerosol-transport model and in-situ measurements

AIP Conf. Proc. 1531, 680 (2013); 10.1063/1.4804861

Impacts of major factors on downward longwave radiation

AIP Conf. Proc. 1531, 608 (2013); 10.1063/1.4804843

Spectrometer and radiative transfer model comparison using high sun in-situ observations in Pretoria AIP Conf. Proc. 1531, 524 (2013); 10.1063/1.4804822

Aerosol properties and radiative forcing for three air masses transported in Summer 2011 to Sopot, Poland AIP Conf. Proc. 1531, 504 (2013); 10.1063/1.4804817

Monitoring precipitation and lightning via changes in atmospheric gamma radiation AIP Conf. Proc. 680, 820 (2003); 10.1063/1.1619837 


\title{
Small-scale Spatial Variations of Shortwave Downward Radiation
}

\author{
Ralf Becker $^{\mathrm{a}}$, Petra Gebauer ${ }^{\mathrm{b}}$ and Klaus Behrens ${ }^{\mathrm{a}}$ \\ ${ }^{a}$ German Weather Service, Meteorological Observatory Lindenberg, Am Observatorium 12, \\ D-15848 Tauche, Germany \\ ${ }^{b}$ Free University Berlin, Meteorological Institute, Carl-Heinrich-Becker-Weg 6-10, D-12165 Berlin, Germany
}

\begin{abstract}
DWD/Meteorological Observatory Lindenberg is operating a small-scale ground-based network of measurement sites for precipitation and shortwave radiation. The area is located roughly $60 \mathrm{~km}$ southeast of Berlin city. 8 measurement sites are equipped with high quality instruments CM21/CM11 by Kipp \& Zonen. The quality assessment routinely applied takes into account the basic astronomical and empirical considerations as well as some interdependencies like total to diffuse flux ratio and cross checking with sunshine duration. Possible shading due to growing vegetation is taken into account, too. This is complemented by an approach that is utilizing time-series of clear sky radiative transfer simulations for every site. For that purpose a link to cloud coverage obtained from Meteosat second generation geostationary satellite data, highly resolved in time and space, was established. The paper provides an overview of the surface radiation network and the current activities to improve automatic quality assessment using remotely sensed data and clear sky modelling.

First evaluation efforts cover up to 12 years of data.
\end{abstract}

Keywords: Ground-based shortwave radiation network, Spatial variability. PACS: $92.60 . \mathrm{Vb}$

\section{INTRODUCTION}

Irradiance is a key parameter in Earth's weather and climate system. Accurate observations of the components of the near surface radiation budget are therefore essential (1) and indispensable for testing, validation and adaptation of satellite-based algorithms. High quality ground-based measurements are performed in the context of the baseline surface radiation network (2). The German Weather Service - Meteorological Observatory Lindenberg is operating the BSRN station at Lindenberg as well as a small sub-network of broadband shortwave downward radiation in the vicinity of the observatory that was originally designed for quantification of energy balances (3). Sites are equipped each with two Kipp \& Zonen CM11 or CM21 pyranometers to measure diffuse (shaded) and total (unshaded) downward shortwave radiation $(0.3-2.8 \mu \mathrm{m})$. Instrumentation is categorized as secondary standard according to ISO 9060 or high quality with respect to WMO classification. For the achievement of a global coverage the utilisation of satellite-based retrievals have become an important part. Such retrievals are developed and data are provided in the framework of EUMETSAT's Satellite Application Facilities like SAF on Climate Monitoring (4) and LandSAF (5).

\section{DATA AVAILABILITY}

The calibration of the field/network pyranometers is performed at the RRC/NRC at Meteorological Observatory Lindenberg (MOL) indoor referring to ISO 9847:1992 "Solar energy - Calibration of field pyranometers by comparison to a reference pyranometer". All calibrations are traceable to world radiation reference (WRR). Data availability is close to $100 \%$ for BSRN and the boundary-layer measurements field Falkenberg. The other sites stand-alone systems equipped with data logger - are maintained on a weekly to monthly basis and therefore more often subject to outages. Such missings are typically related to severe weather like thunderstorms or snow and ice. An overview of almost complete datasets used for this evaluation is given in Table 1. A land use map showing with the sites pinned is displayed in Figure 1. 
TABLE (1). Overview of site's data availability. It refers to almost complete yearly datasets.

\begin{tabular}{|c|c|c|}
\hline Station name & $\begin{array}{l}\text { Station } \\
\text { number }\end{array}$ & Data availability \\
\hline $\begin{array}{l}\text { Lindenberg } \\
\text { (BSRN) }\end{array}$ & 3015 & $2000-2011$ \\
\hline Falkenberg & 5810 & $2000-2011$ \\
\hline Storkow & 20147 & $\begin{array}{c}2000,2001,2003, \\
2007-2011\end{array}$ \\
\hline Wendisch-Rietz & 20146 & $\begin{array}{c}2001,2003,2007- \\
2011\end{array}$ \\
\hline Wald & 20106 & $2003-2011$ \\
\hline Limsdorf & 20132 & $2001,2007-2011$ \\
\hline Werder & 20140 & $\begin{array}{c}2001,2002,2007- \\
2011\end{array}$ \\
\hline Neu-Luebbenau & 20149 & $2003,2007-2011$ \\
\hline
\end{tabular}

FIGURE (1). Map of the Pyranometer network.

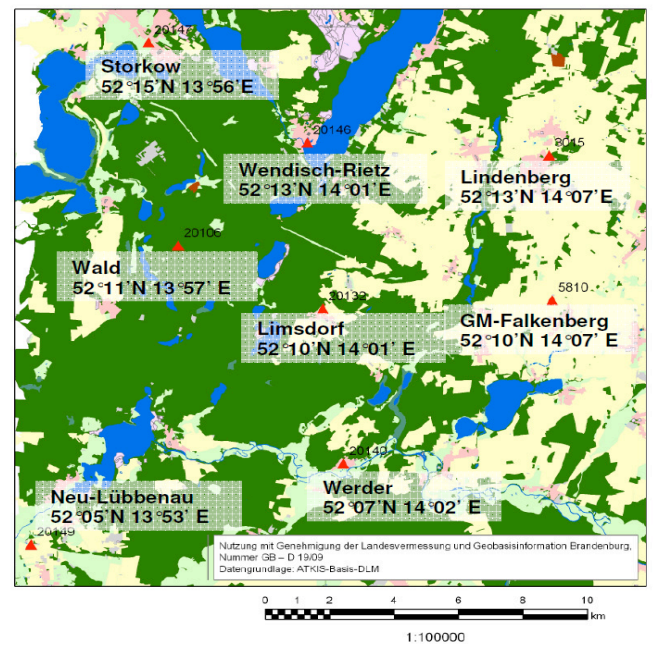

\section{QUALITY ASSESSMENT}

The quality assessment routinely applied takes into account the basic astronomical and empirical considerations as well as some inter-dependencies like total to diffuse flux relation. A more advanced approach attempts to utilize timeseries of clear sky radiative transfer simulations for every site. For that purpose a link to cloud coverage obtained from Meteosat second generation geostationary satellite data, highly resolved in time and space, was established.

Simulations of arbitrary meteorological scenes requires detailed input of microphysical cloud properties that can hardly be provided in appropriate quality for the whole region of interest. Best matches between calculated and measured quantities can be expected for clear-sky conditions when direct income dominates the global component. The time frame is restricted from 10 to 13 UTC. Calculation of downward shortwave radiation is done using radiation transfer code Streamer (6).

Satellite input is used as an independent source for the identification of daylight clear sky phases. Meteosat second generation (MSG) is carrying the SEVIRI instrument, a 12 channel radiometer, scanning absorbing and nonabsorbing bands of the visible and infrared part of the spectrum every 15 minutes on a spatial scale of appr. $3 \mathrm{~km} * 5$ $\mathrm{km}$ (7). To obtain cloud information (cloud mask, cloud type) on pixel level a multispectral thresholding scheme is used. The decision on clear sky conditions based on satellite input may differ to other sources like analysing radiation data itself or additional sunshine recording (Campbell-Stokes, SONIe). Fair weather small scale cumulus clouds (cumulus humilis) may be missed, but cirrus clouds affecting direct and diffuse radiation (unaffecting sunshine recording) are detected.

The standard setup for the model only roughly distinguishes between winter and summer mid-latitude atmosphere and runs with climatological ozone and background tropospheric aerosol. It is extended optionally to feed in alternatively measured profiles (radiosoundings, microwave profilings, integrated quantities for aerosol and ozone). For the comparison study data of pyranometer sites of the period May 2010 to August 2011 were selected, resulting in a total number of 560 cases. The model tends to give higher estimates - indicated by a relative bias of 1.02 - even though some negative deviations are present, too. Systematic deviation is $+2.40 \% \quad 3.36 \%$ for pyranometer sites. The plots in Figure 2 display the 12-year time series of measurement to model comparison for site 5810 (Falkenberg). 

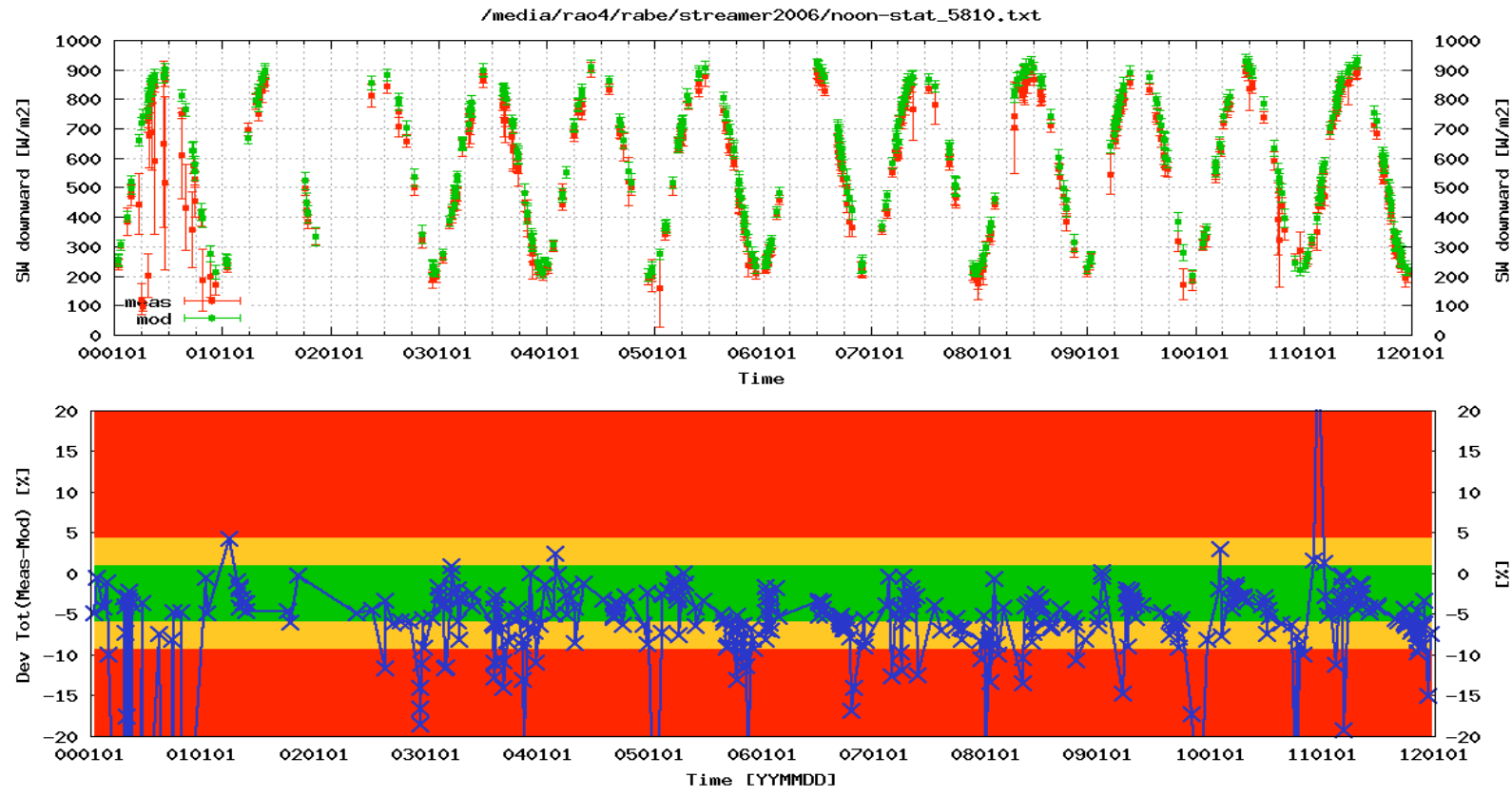

FIGURE 2. a.) Upper panel: timeserie of clear-sky measurement to model comparison for boundary-layer measurements field Falkenberg. Commencing in 2001 there is good correspondence in general. b) lower panel: relative deviation measurement to model. Green bar denotes bias plus/minus sigma, yellow plus/minus two sigma.
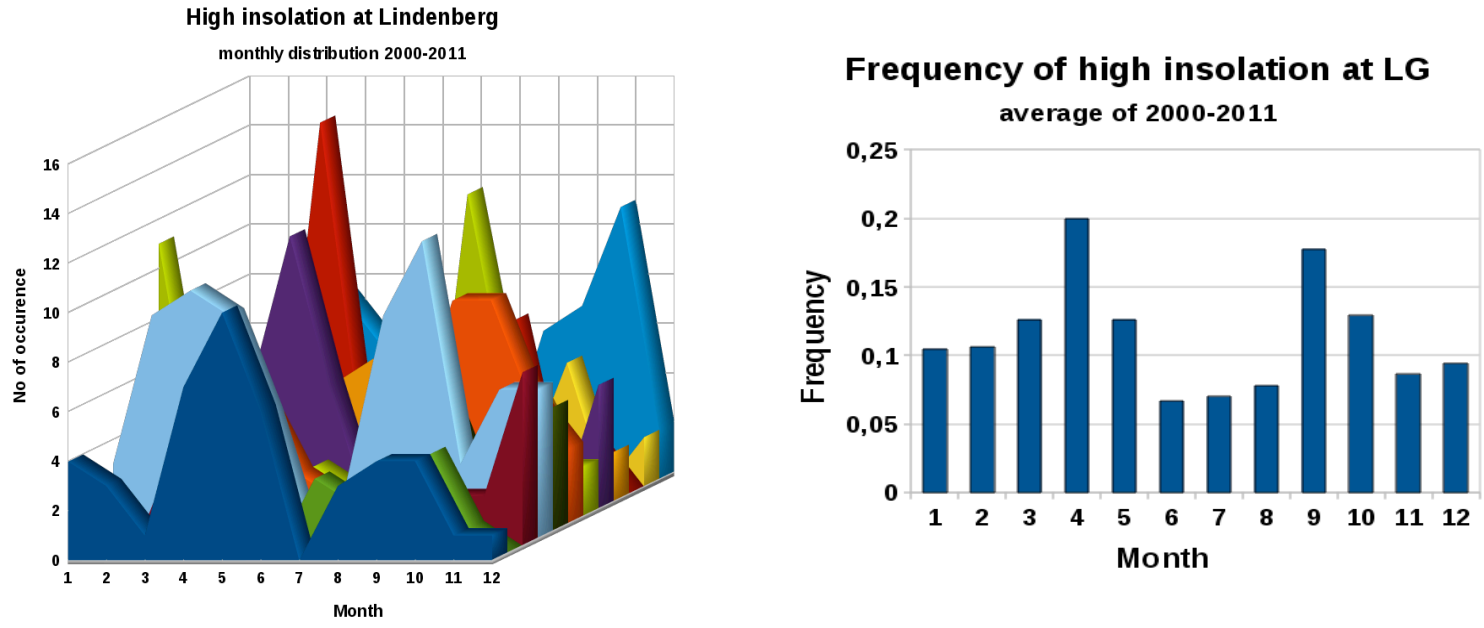

FIGURE 3. a.) left: number of occurrence of days with high insolation at Lindenberg per month in the time range 2000 to 2011. The label 'high insolation' refers to possible daily maximum amount, b) right: taken a), condensed to monthly frequency.

\section{SPATIAL VARIABILITY: FIRST RESULTS}

TABLE (2). Statistics of instantaneous values, all conditions, 2004-2007, referenced to BSRN Lindenberg.

$\begin{array}{lcccc}\text { Station name } & \text { Correlation } & \text { Bias } & \text { Mean absolute bias } & \text { Rmse } \\ \text { Falkenberg } & .96 & -1.0 & 8.4 & 87.2 \\ \text { Storkow } & .95 & +2.2 & 10.9 & 105.1\end{array}$


Monthly sums of global radiation are calculated and results of maximum 8 sites are mapped to the $20 \mathrm{x} 20 \mathrm{~km}^{2}$ region. Missing data is causing rejection of site's data. Sums may differ up to $3 \mathrm{~kJ} / \mathrm{cm}^{2}$ for a month that can be characterized by high insolation like July 2003. Differences are smaller in August 2003. Distinct maxima are observed at Lindenberg and Limsdorf (both months), minima at Waldstation (July) and Falkenberg (August, see Figures $4 \mathrm{a}$. and 4b.)
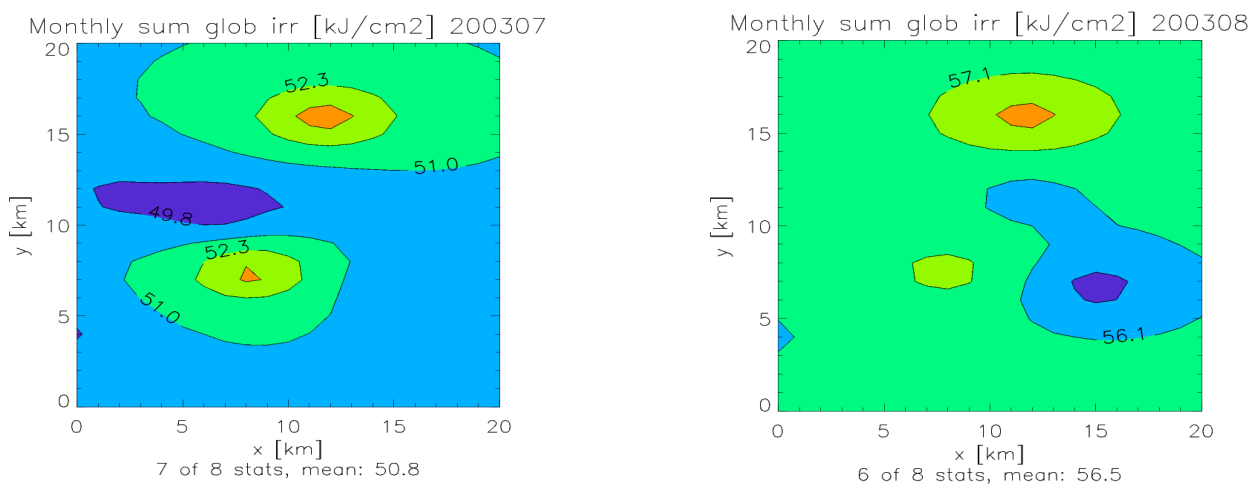

FIGURE 4. (a) Monthly sums of global radiation July 2003, (b) same for August 2003.

\section{CONCLUSION AND OUTLOOK}

Careful quality assessment turns out to be crucial for this kind of investigation. A lot of 'doubtful' data might be OK for most conditions except clear-sky, therefore we are facing a remarkable reduction of data availability. Moreover, careful selection of data for clear-sky simulations is needed: different criteria for the identification of clear-sky phases sometimes give contrary results. A combination of criteria is useful, for instance sunshine duration plus Meteosat cloud cover on site. In general, there is good correspondence of field data to BSRN reference. Spatial variability of the order of $3 \mathrm{~kJ} / \mathrm{cm}^{2}$ could be detected for sunny months in 2003 . Further investigation and verification is needed here.

\section{ACKNOWLEDGMENTS}

Maintenance of the radiation instruments is done on a regular basis by the boundary-layer group of the Meteorological Observatory Lindenberg. Special thanks to P. Dereszynski for providing all regarded meta-info and first level quality assessment and to $\mathrm{C}$. Heret for providing high-resolution landuse map of the region.

\section{REFERENCES}

1. IPCC, Climate Change: The Physical Science Basis. Contribution of Working Group I to the Fourth Assessment Report of the Intergovernmental Panel on Climate Change, edited by: S. Solomon, D. Qin, M. Manning, Z. Chen, M. Marquis, K. B. Avery, M. Tignor and H. L. Miller, Tech. rep., Cambridge Univ. Press, UK (2007).

2. A. Ohmura, E. Dutton, B. Forgan, C. Froehlich, H. Gilgen, H. Hegner, A. Heimo, G. Koenig-Langlo, B. McArthur, G. Mueller, R. Philipona, R. Pinker, C. Whitlock, K. Dehne and M. Wild, B. Am. Meteorol. Soc. 79, 2115-2136 (1998).

3. F. Beyrich, H. J. Herzog and J. Neisser, Theoretical and Applied Climatology 73, No. 1-2 (2002), 3-18.

4. R. Mueller, C. Matsoukas, A. Gratzki, H. D. Behr and R. Hollmann, Remote Sens. Environ. 113, 1012-1024 (2009).

5. I. F. Trigo, C. DaCamara, P. Viterbo, J. Roujean, F. Olesen, C. Barroso, F. Camacho-de Coca, D. Carrer, S. Freitas, J. GarcíaHaro, B. Geiger, F. Gellens-Meulenberghs, N. Ghilain, J. Melia, L. Pessanha, N. Siljamo and A. Arboleda, Int. J. Remote Sens. 32, 2725-2744 (2011).

6. J. Key, Streamer User's Guide, Tech. rep., Cooperative Institute for Meteorological Satellite Studies, 96 pp., 2001.

7. J. Schmetz, P. Pili, S. Tjemkes, D. Just, J. Kerkmann, S. Rota and A. Ratier, B. Am. Meteorol. Soc. 83, 977-992 (2002). 